\title{
Beta-tubulin Isotype 1 Conferred Benzimidazole-resistance in Lymphatic Filariasis: an Explanation by Molecular Concern
}

\section{Viroj Wiwanitkit ${ }^{\star}$}

Department of Medicine, Hainan Medical University, Hainan Sheng, PR China

The lymphatic filariasis is an important lymphatic disease. It is the well-known lymphatic vessel disorder due to infection by a blood parasitic pathogen. The nematode parasite transmitted by mosquito is the cause of filariasis which can further result in severe disability in chronic infected cases. The filariasis is accepted as an important but forgotten tropical mosquito borne infection. The disease can be chronic and result in permanent disability, the elephantaiasis. At present, this disease is still endemic in several tropical regions around the world. The management of filiariasis can be by using antiparasitic drug. The Albendazole, anthelmintic benzimidazole (BZ) is generally used concomitant with diethylcarbamazine, in lymphatic filariasis management. Schwab et al. mentioned that "The Global Program for the Elimination of Lymphatic Filariasis intends to achieve its aims through yearly mass treatments with BZ combined with ivermectin (IVM) or diethylcarbamazine (DEC) [1]."

However, the resistance to $\mathrm{BZ}$ can be observed in clinical practice. The role of genetic polymorphism underlying the $\mathrm{BZ}$ resistance is of interest. There are some reports mentioning for some genetic polymorphisms of the parasite that can contribute to resistance to NZ. The mutation that results in replacement of phenylalanine (Phe) with tyrosine (Tyr) at position 200 of beta-tubulin isotype 1 is reported to be related to resistance to BZ [2-3]. As noted by Hoti et al. monitoring of this point genetic variant is suggested for monitoring of drug resistance of filariasis in endemic area [2]. The observed pattern of the mutation in each setting can refer to the drug resistance epidemiology in each specific area and can also a predictor for the success of treatment. The available PCR tool can be applied for such investigation of the mutation that can confer to the BZ resistance of the filarial pathogen [3]. Cobo concludes that "widespread of resistance to $\mathrm{BZ}$ is present because specific mutations in the gene encoding $\beta$-tubulin have been associated with drug resistance [4]."

The mechanism conferring to the resistance is very interesting. Here, the author used the quantum molecular approach for explanation for the observed resistance due to the mentioned mutation. Briefly, when the mentioned mutation, 200 Phe -> Tyr occurs, the molecular change from naïve molecule of beta-tubulin isotype 1 can be expected. The quantum calculation for the molecular weight change can be done and the derived change magnitude is $16 \mathrm{Da}$ per mol. As described in previous similar studies on quantum molecular estimation for the genetic variant change in other disorders [5-8], the change in the present scenario of beta-tubulin isotype $1 \mathrm{can}$ also affect the final pharmaco-biological process between BZ drug and filarial parasite. The increased molecular weight can imply more required molecular reaction energy between drug and parasite. This can further results in increased difficulty in successful drug pharmacological action. Hence, the mentioned 200 Phe ->Tyr mutation of beta-tubulin isotype 1 can pose resistance property to BZ. This short study can well clarify the myth about the resistance to $\mathrm{BZ}$ of tropical filarial parasite, which is still the problem in management of filiarisis at present [9].

\section{References}

1. Schwab AE, Churcher TS, Schwab AJ, Basáñez MG, Prichard RK (2006) Population genetics of concurrent selection with albendazole and ivermectin or diethylcarbamazine on the possible spread of albendazole resistance in Wuchereria bancrofti. Parasitology 133: 589-601.

2. Hoti SL, Subramaniyan K, Das PK (2003) Detection of codon for amino acid 200 in isotype 1 beta-tubulin gene of Wuchereria bancrofti isolates, implicated in resistance to benzimidazoles in other nematodes. Acta Trop 88: 77-81.

3. Hoti SL, Dhamodharan R, Subramaniyan K, Das PK (2009) An allele specific PCR assay for screening for drug resistance among Wuchereria bancrofti populations in India. Indian J Med Res 130:193-199.

4. Cobo $F(2016)$ Determinants of parasite drug resistance in human lymphatic filariasis. Rev Esp Quimioter 29: 288-295.

5. Schwab AE, Boakye DA, Kyelem D, Prichard RK (2005) Detection of benzimidazole resistance-associated mutations in the filarial nematode Wuchereria bancrofti and evidence for selection by albendazole and ivermectin combination treatment. Am J Trop Med Hyg 73: 234-238.

6. Wiwanitkit $V(2009)$ Analysis of binding energy activity of imatinib and $A b$ tyrosine kinase domain based on simple consideration for conformational change: An explanation for variation in imatinib effect in mutated type. Indian J Cancer 46: 335-336.

7. Joob B, Wiwanitkit V (2016) ATP-binding cassette, sub-family $B$ (MDR/TAP), member 1 (ABCB1) polymorphism and clopidogrel concentration in acute coronary syndrome: molecular change can explain the observed therapeutic concentration. Anatol J Cardiol 16: 303-304.

8. Joob B, Wiwanitkit V (2016) HSD11B1 rs846908 polymorphisms and tacrolimus concentrations: quantum chemical analysis and implication in patients with renal transplantation. J Nephropharmacol 6: 19-20.

9. McCarthy $J$ (2015) Is anthelmintic resistance a threat to the program to eliminate lymphatic filariasis? Am J Trop Med Hyg 73: 232-233.

Corresponding author: Wiwanitkit $\mathrm{V}$, Hainan Medical University, Hainan Sheng, PR China, Tel: +86 8986689 3610; E-mail: wviroj@yahoo.com

Received August 03, 2017; Accepted August 14, 2017; Published August 24 2017

Citation: Wiwanitkit V (2017) Beta-tubulin Isotype 1 Conferred Benzimidazoleresistance in Lymphatic Filariasis: an Explanation by Molecular Concern. J Blood Lymph 7: e123. doi: 10.4172/2165-7831.1000e123

Copyright: $\odot 2017$ Wiwanitkit V. This is an open-access article distributed unde the terms of the Creative Commons Attribution License, which permits unrestricted use, distribution, and reproduction in any medium, provided the original author and source are credited. 